\title{
The influence of emotional intelligence on diversity complexity cognition and the attitude towards diversity
}

\author{
J.M. Kamps and A.S. Engelbrecht* \\ Department of Industrial Psychology, University of Stellenbosch, \\ Stellenbosch 7600, Republic of South Africa \\ ase@sun.ac.za
}

Received September 2010

\begin{abstract}
The aim of the study was to develop and validate a theoretical model explicating the structural relationships between diversity complexity cognition, emotional intelligence and a positive attitude towards diversity in the South African business context. The sample selected for the study consisted of 237 employees from various South African organisations. The content and structure of the latent variables were investigated by means of item analysis, as well as confirmatory and exploratory factor analysis. The results of structural equation modelling (SEM) demonstrated good model fit for the refined measurement models and the structural model. A positive relationship was found between emotional intelligence and the latent variables of valuing individual differences and positive perceptual depth. The practical implications were highlighted to ultimately inform management seeking to build an ethically diverse and productive workforce that values the individuality of others.
\end{abstract}

*To whom all correspondence should be addressed.

\section{Introduction}

Workplace diversity is an increasing reality and organisations need to be able to manage this phenomenon successfully, as this diversity is also becoming increasingly complex (Homan, Van Knippenberg, Van Kleef \& De Dreu, 2007; Hostager \& De Meuse, 2008; Roberson \& Stevens, 2006; Seyman, 2006; Yukl, 2010). The South African history of apartheid and, discrimination and predicaments arising with regard to the management of diversity have made workplace diversity a critical challenge that faces South African organisations today (Boon, 2007; Human, 2005).

If organisations could identify the antecedents of a positive attitude towards diversity, these organisations could develop employee skills vital to effective social interaction and team work (Homan et al., 2007; Sanchez-Burks, Blount \& Bartel, 2009; Sawyerr, Strauss \& Yan, 2005; Seyman, 2006; Strauss, Connerley \& Ammermann, 2003).

The need for a better understanding of how members of an organisation make sense of diversity has therefore also increased, because particular interpretations by members may promote tolerance for diversity and assist conflict resolution (Roberson \& Stevens, 2006). The multidimensionality of an individual exhibiting a high level of cognition of diversity complexity allows for differentiation and integration as part of the information processing activity at the social level (Human, 1996a). Perceptions that are more complex cover multiple aspects of diversity. This enables an individual to relegate sub-group differences into second-order factors, in favour of shared values, beliefs and attitudes (Fiske \& Lee, 2008; Hostager \& De Meuse, 2008).

Emotional intelligence plays a fundamental role in the establishment and management of employee relationships (Elfenbein \& Ambady, 2002). Employees with high levels of emotional intelligence are able to master their interactions with diverse others in a more effective manner and, as a result, maintain a more positive attitude towards diversity (Antonakis, Ashkanasy \& Dasborough, 2009; Murphy \& Janeke, 2009). Harvey and Allard (2005: 47) similarly contend that "emotional intelligence is one key to developing the ability to manage and appreciate individual differences".

\section{Aim of the study}

The aim of the study was to develop and validate a theoretical model explicating the structural relationships between diversity complexity cognition, emotional intelligence and a positive attitude towards diversity in the South African business context. The research question initiating this investigation was: Does emotional intelligence and diversity complexity cognition provide a valid and permissible account of the attitude towards diversity that people maintain in the workplace?

The relationship between emotional intelligence and attitude towards diversity 
Emotional Intelligence (EI) can be defined as the capacity to deal effectively with one's own emotions and with those of others, which involves the capacity to perceive, express, understand and manage emotions in a professional and effective manner at work (Palmer \& Stough in Gignac, 2008). According to Rentsch, Turban, Hissong, Jenkins and Marrs (1995), a positive attitude towards diversity refers to an awareness of, respect for and valuing of differences among individuals that permits one to truly value and appreciate diverse others.

According to Cottrell and Neuberg (2005), a generally negative attitude towards different groups, can fortify negative emotional responses towards others (i.e. fear, anger, distrust). However, individuals exhibiting high EI are more inclined to view the diversity of others in a more positive manner, because they are more accepting of, and find value in, the differences of others (Carmeli, 2003; Antonakis et al., 2009).

Employees with lower levels of EI may be less able to express and control their emotions appropriately, which could result in more negative attitudes and interpersonal interaction. Employees with high levels of EI accordingly maintain a more positive attitude towards their diverse coworkers and may experience less interpersonal conflict than those who have lower levels of EI (Murphy \& Janeke, 2009; Suliman \& Al-Shaikh, 2007).

On the basis of the above arguments, it was postulated that emotional intelligence is positively related to a positive attitude towards diversity.

\section{The relationship between an attitude towards diversity and diversity complexity cognition}

Diversity complexity cognition refers to the degree to which an individual's view of diversity is differentiated across aspects of diversity (Hostager \& De Meuse, 2002). An individual's perception of diversity can be represented along a continuum of complexity and inclusiveness, reflecting the degree to which different social identities are both differentiated and integrated in the individual's cognitive representation of his or her group memberships (Brewer \& Pierce, 2005). Thus, diversity complexity cognition comprises the ability to make sense of diversity.

Individuals who display a high level of diversity complexity cognition tend to be more moderate in their attitudes, are more open to disconfirming information, and to the need to readjust their thinking. They are thought to be better discerners of the attitudes and intentions of others in facilitating fluent, efficient interaction and helping others utilise their diverse abilities to accomplish their collective goals (Heine, Proulx \& Vohs, 2006; Polzer \& Caruso, 2008).

Low diversity complexity cognition is likely to be accompanied by negative reactions to diversity along emotional, behavioural and cognitive lines (Hostager \& De Meuse, 2008). Individuals who display this are unable to appreciate others for their diverse attributes and are likely to maintain the perception that any individual who is an out- group member on one dimension is also an out-group member on all others.

Individuals who are able to comprehend that they belong to more than one in-group and that their multiple in-group categories do not converge, will show a higher level of diversity complexity cognition and will therefore be more tolerant of out-group members.

Based on the above theoretical arguments, it was postulated that a positive attitude towards diversity is positively related to diversity complexity cognition.

\section{The relationship between emotional intelligence and diversity complexity cognition}

People differ with regard to their ability to understand the complexities of diversity in terms of a number of aspects, including beliefs and emotions (Cottrell \& Neuberg, 2005). In a study conducted by DeGuara and Stough (2002), employees who could perceive and understand the emotions of their colleagues were considered to be more understanding and sensitive towards others, while effective control over their emotional states allowed them to work better in teams.

Individuals with a high level of empathy will be able to understand others' sensitivities, which will enable them to anticipate a negative emotional reaction in another individual, and avoid behaviours that could trigger negative emotions in others (Gignac, 2008; Goleman, Boyatzis \& McKee, 2002).

Salovey and Mayer (1990) found that team members with high levels of EI are more able to monitor their own and others' emotions, while simultaneously being able to discriminate among and guide their thoughts and actions. Individuals who display a high level of diversity complexity cognition are more likely to recognise emotions in others, because they have acknowledged a difference between themselves and others and have made some attempt to understand why this difference exists (Plaut, 2002)

Based on the arguments presented above, it was postulated that emotional intelligence is positively related to diversity complexity cognition.

\section{Theoretical model}

After an in-depth investigation of the literature covering the relationships between emotional intelligence, diversity complexity cognition and the attitude towards diversity, a conceptual model was derived. Emotional intelligence was proposed as the exogenous latent variable, with diversity complexity cognition and a positive attitude towards diversity as the endogenous latent variables.

Upon examination of the conceptual model, it was noted that certain dimensions of the attitude towards diversity (i.e. valuing individual differences, a tolerance of affirmative action and diversity as a competitive advantage) and diversity complexity cognition (i.e. perceptual breadth, 
positive and negative perceptual depth) operate independently to that of the overall constructs.

Figure 1 illustrates the conceptual model that depicts the specific paths or hypothesised causal linkages between emotional intelligence, the dimensions of diversity complexity cognition and the dimensions of attitude towards diversity.

\section{Statistical hypotheses}

Hypothesis 1: The overarching research hypothesis was interpreted to imply that the structural model depicted in Figure 1 provides an approximate account of the manner in which emotional intelligence influences diversity complexity cognition and an individual's attitude towards diversity in organisations. The substantive research hypothesis can be translated into the following close fit null hypothesis:

$\mathrm{H}_{01}: \mathrm{RMSEA} \leq 0,05$

$\mathrm{H}_{\mathrm{a} 1}: \mathrm{RMSEA}>0,05$

If $\mathrm{H}_{01}$ would not be rejected (or at least if reasonable model fit would be obtained), the overarching substantive research hypothesis, as represented by the paths hypothesised in Figure 1, would be tested by the following nine hypotheses:

Hypothesis 2: Positive perceptual depth $\left(\eta_{3}\right)$ is significantly and positively related to perceptual breadth $\left(\eta_{1}\right)\left(\mathrm{H}_{02}: \beta_{13}=\right.$ $0 ; \mathrm{H}_{\mathrm{a} 2}: \beta_{13}>0$ ).

Hypothesis 3: Negative perceptual depth $\left(\xi_{2}\right)$ is significantly and positively related to perceptual breadth $\left(\eta_{1}\right)\left(\mathrm{H}_{03}: \gamma_{12}=\right.$ $\left.0 ; \mathrm{H}_{\mathrm{a} 3}: \gamma_{12}>0\right)$.

Hypothesis 4: Valuing individual differences $\left(\eta_{2}\right)$ is significantly and positively related to perceptual breadth $\left(\eta_{1}\right)\left(\mathrm{H}_{04}: \beta_{12}=0 ; \mathrm{H}_{\mathrm{a} 4}: \beta_{12}>0\right)$.
Hypothesis 5: Emotional intelligence $\left(\xi_{1}\right)$ is significantly and positively related to perceptual breadth $\left(\eta_{1}\right)\left(\mathrm{H}_{05}: \gamma_{11}=\right.$ $\left.0 ; \mathrm{H}_{\mathrm{a} 5}: \gamma_{11}>0\right)$.

Hypothesis 6: Emotional intelligence $\left(\xi_{1}\right)$ is significantly and positively related to positive perceptual depth $\left(\eta_{3}\right)\left(\mathrm{H}_{06}\right.$ : $\left.\gamma_{31}=0 ; \mathrm{H}_{\mathrm{a} 6}: \gamma_{31}>0\right)$.

Hypothesis 7: Emotional intelligence $\left(\xi_{1}\right)$ is significantly and positively related to valuing individual differences $\left(\eta_{2}\right)$ $\left(\mathrm{H}_{07}: \gamma_{21}=0 ; \mathrm{H}_{\mathrm{a} 7}: \gamma_{21}>0\right)$.

Hypothesis 8: Valuing individual differences $\left(\eta_{2}\right)$ is significantly and positively related to positive perceptual depth $\left(\eta_{3}\right)\left(\mathrm{H}_{08}: \beta_{32}=0 ; \mathrm{H}_{\mathrm{a} 8}: \beta_{32}>0\right)$.

Hypothesis 9: Valuing individual differences $\left(\eta_{2}\right)$ is significantly and positively related to tolerance of affirmative action $\left(\eta_{4}\right)\left(\mathrm{H}_{09}: \beta_{42}=0 ; \mathrm{H}_{\mathrm{a} 9}: \beta_{42}>0\right)$.

Hypothesis 10: Valuing individual differences $\left(\eta_{2}\right)$ is significantly and positively related to competitive advantage $\left(\eta_{5}\right)\left(\mathrm{H}_{010}: \beta_{52}=0 ; \mathrm{H}_{\mathrm{a} 10} \beta_{52}>0\right)$.

Hypothesis 11: The relationship between emotional intelligence and tolerance towards affirmative action is mediated by valuing individual differences (H7 \& H9).

Hypothesis 12: The relationship between emotional intelligence and diversity as a competitive advantage is mediated by valuing individual differences (H7 \& H10).

Hypothesis 13: The relationship between emotional intelligence and perceptual breadth is mediated by positive perceptual depth (H6 \& H2).

Hypothesis 14: The relationship between valuing individual differences and perceptual breadth is mediated by positive perceptual depth (H8 \& H2).

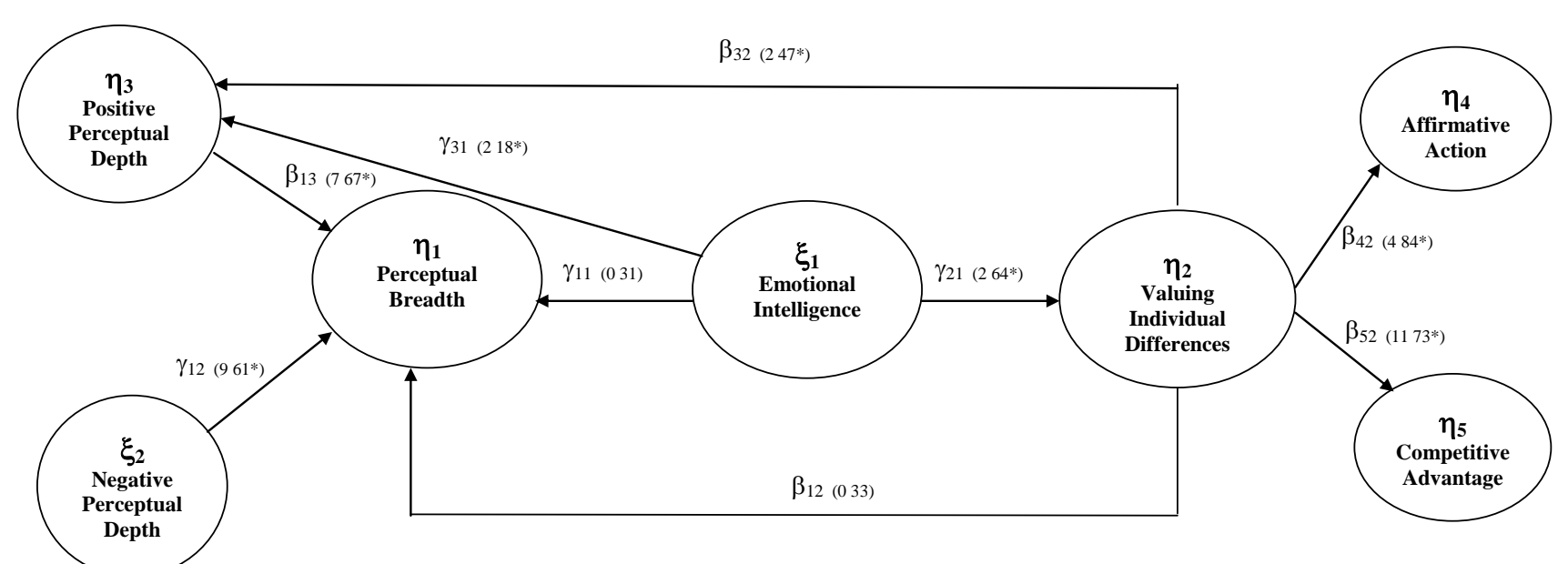

$* t$-values $\geq|1.96|$ indicate significant path coefficients $(\mathrm{p}<0,05)$

Figure 1: The conceptual structural model 


\section{Research methodology}

\section{Sample}

The present study made use of non-probable sampling. The convenient sample consisted of 237 employees operating within various organisations within South Africa. The sample consisted of 140 female $(59,1 \%)$ and 97 male $(40,9 \%)$ employees. The average age of respondents was 36.5 years, while the race distribution in the sample was: Non-whites $(39,2 \%)$ and whites $(60,8 \%)$. Regarding highest level of qualification, the majority of respondents had 12 years of schooling $(38,8 \%)$. The majority of respondents were employed in Health and Welfare Services (20,3\%); while several industries were represented through percentages in excess of $5 \%$ of the sample (e.g. Security Services, Financial Services, Food and Beverages, Manufacturing, and Retail).

\section{Measuring instruments}

The constructs of attitude towards diversity, emotional intelligence and diversity complexity cognition were measured with the Cultural Diversity Belief Scale (CDBS), the Genos Emotional Intelligence Inventory (Genos EI) and the Reaction-To-Diversity-Inventory (RTDI), respectively.

\section{Attitude towards diversity: CDBS}

The CDBS developed by Rentsch et al. (1995), was used as a means of measuring an individual's attitude towards diversity in the workplace. The CDBS contains 23 Likerttype scale items designed to tap three postulated diversity belief dimensions: (1) valuing individual differences; (2) diversity as a competitive advantage; and (3) tolerance of affirmative action.

The three dimensions of diversity beliefs were identified through exploratory factor analysis (EFA). Overall internal consistency coefficients of 0.82 and 0.77 were found in two samples (Rentsch et al., 1995), indicating acceptable reliability (Nunnally, 1978).

\section{Emotional intelligence: Genos EI}

EI was measured using the Genos EI developed by Gignac (2008). The Genos model of EI comprises a general factor (Overall EI), described by seven orthogonal factors: Emotional Self-Awareness (ESA), Emotional Expression (EE), Emotional Awareness of Others (EAO), Emotional Reasoning (ER), Emotional Self-Management (ESM), Emotional Management of Others (EMO) and Emotional Self-Control (ESC). Each of the seven factors is measured by 10 homogenous emotionally intelligent work behaviours (i.e. items).

Gignac (2008) reported mean subscale reliabilities $(\alpha)$ ranging from 0,71 to 0,85 across five nationalities (American, Australian, Asian, Indian and South African). The mean Genos EI total score internal consistency reliability $(\alpha)$ was estimated at 0,96 . It was further found that test-retest correlations of the Genos Total EI scores were associated with reliability coefficients of 0,83 and 0,72 , based on two-month and six-month time intervals.

\section{Diversity complexity cognition: RTDI}

In order to assess the cognition of diversity complexity, this study made use of De Meuse and Hostager's RTDI (De Meuse \& Hostager, 2001). De Meuse and Hostager (2001) identified the following five categories representing the range of positive and negative reactions to workplace diversity: Emotional Reactions; Judgements; Behavioural Reactions; Personal Consequences; and Organisational Outcomes. The RTDI includes 70 words (items), with each word depicting either a positive or a negative response to one of the five dimensions.

Individuals who perceive diversity as involving at least one item in each of the five categories demonstrate diversity complexity cognition in the form of perceptual breadth (Hostager \& De Meuse, 2002). On the other hand, using multiple items to represent each category measures a second form of diversity complexity cognition - perceptual depth. Counting the number of positive words circled on the inventory provides an index of the degree to which participants view diversity in a positive light (positive perceptual depth). Similarly, counting the number of negative words circled, yields a measure of the extent to which diversity is perceived in a negative light (negative perceptual depth).

Subsequent to the development of the RTDI, De Meuse and Hostager (2001) developed a shorter version (20 items) of this instrument, namely the Workplace Diversity Survey (WDS). Data obtained from the administration of the WDS revealed a high level of convergent validity of the RTDI ( $r=$ $0,51, \mathrm{p}<0,001$ ) (De Meuse \& Hostager, 2001).

\section{Research results}

\section{Missing values}

Missing values presented a problem that had to be addressed before the analysis could proceed. The PRELIS programme (Jöreskog \& Sörbom, 1996) was used to impute such missing values. After imputation, 237 of the original 242 cases, with observations on all the items included in the questionnaire, remained in the validation sample.

\section{Evaluating the measurement models}

LISREL 8.54 (Jöreskog \& Sörbom, 1996) was used to perform initial confirmatory factor analyses (CFA) on each of the sub-scales of the various instruments used in this study. The initial test of the validity of the measurement models was based on two important fit indices, namely the p-value Test of Close Fit and RMSEA, where $p>0,05$ and RMSEA $<0,08$ indicate good model fit (Hair, Black, Babin, Anderson, \& Tatham, 2006; Kelloway, 1998).

If poor model fit was found, an EFA was performed on the specific sub-scale to identify any poor items (i.e. factor loadings < 0,30; complex items), using SPSS. The application of the eigenvalues-greater-than-unity rule was 
used to identify the number of factors that underlie the observed correlation matrix for the subscale.

After deletion of the poor items, a further CFA was performed on the refined scale. Once a satisfactory fit was achieved, any item with an inadequate completely standardised factor loading $(<0.30)$ was also deleted (Hair et al., 2006).

\section{Goodness-of-fit: The refined CDBS measurement models}

Having distilled the most meaningful factor structures within the responses of the present sample, via both CFA and EFA procedures, the final step in the analysis was to examine the goodness-of-fit statistics for each of the final item structures of the three respective CDBS dimensions. In order to fully evaluate the measurement model's fit with the data, it was decided that the most important absolute and incremental fit indices be reported (see Table 1).

A comparison of the indices reported in Table 1 indicates that the refined structure of each dimension presents good fit with the data (Hair et al., 2006; Kelloway, 1998). In terms of the Goodness-of-Fit indices, the $\chi^{2} / \mathrm{df}$ ratio $(0,175-$ $1,835)$ for the refined measurement models failed to come close to the 2 to 5 range that is indicative of acceptable fit. As recommended by Kelloway (1998), it is important not to rely solely on the $\chi^{2} / \mathrm{df}$ ratio, but to rather take into account a range of indices. The RMSEA has indeed suggested that the refined measurement models fit the obtained data adequately $(0,0-0,059)$, as values $<0,08$ represent good model fit. The p-value for Test of Close Fit (RMSEA < 0,05 ) varied between 0,33 and 0,91 and therefore the null hypothesis of close fit was not rejected and the various measurement models can be said to show close fit. The RMR of 0,025 to 0,065 indicates reasonable fit, falling inside the 0,08 threshold. Because the RMR is known to be a somewhat unreliable index, the standardised RMR values of 0,0095 to 0,053 provide a more stable figure and, in this instance, are indicative of a good model fit $(<0,05)$. The GFI values for each of the measurement models are close to $1,0(0,95-1,0)$, indicating that good fit has been achieved, as each dimension has reached the $>0,90$ level required to indicate good fit.

The results of the incremental fit measures indicate that, when compared to a baseline model, all three refined measurement models achieve NFI, NNFI, AGFI, CFI, IFI and RFI indices that are $>0,90$, which represents good fit (Hair et al., 2006; Kelloway, 1998). These relative indices therefore appear to portray a positive picture of model fit.

\section{Goodness-of-fit: The refined Genos EI measurement models}

Having distilled the most meaningful factor structures of the dimensions of the Genos EI, the final step in the analysis was to analyse the individual fit of each measurement model after the final CFA on the refined sub-scales. The respective goodness-of-fit indices are illustrated in Table 2.

A comparison of the indices reported in Table 2 indicates that the refined structure of each dimension presents acceptable model fit with the data.

\section{Evaluating the measurement model fit of perceptual breadth}

In this study, Perceptual Breadth was assessed on two levels: category breadth and cell breadth, of which each subscale comprised only one item. As such, factor analysis could not be performed on this particular measure of diversity complexity to test its measurement model. This is a limitation of the present study and any further analyses regarding perceptual breadth should be interpreted with caution.

Table 1: Confirmatory factor analysis fit indices obtained for the refined CDBS measurement models

\begin{tabular}{|c|c|c|c|}
\hline INDICES & VID & $\mathbf{C A}$ & $\mathbf{A A}$ \\
\hline \multicolumn{4}{|c|}{ ABSOLUTE FIT MEASURES } \\
\hline$\chi^{2} / \mathrm{df}$ & 1,556 & 1,835 & 0,175 \\
\hline Root Mean Square Error of Approx. (RMSEA) & 0,049 & 0,059 & 0,0 \\
\hline P-Value for Test of Close Fit (RMSEA < 0.05$)$ & 0,49 & 0,33 & 0,91 \\
\hline Root Mean Square Residual (RMR) & 0,065 & 0,050 & 0,025 \\
\hline Standardised RMR & 0,053 & 0,032 & 0,0095 \\
\hline Goodness of Fit Index (GFI) & 0,95 & 0,99 & 1,00 \\
\hline \multicolumn{4}{|c|}{ INCREMENTAL FIT MEASURES } \\
\hline Normed Fit Index (NFI) & 0,95 & 0,97 & 1,00 \\
\hline Non-Normed Fit Index (NNFI) & 0,98 & 0,96 & 1,00 \\
\hline Adjusted Goodness of Fit (AGFI) & 0,91 & 0,96 & 0,99 \\
\hline Comparative Fit Index (CFI) & 0,98 & 0,99 & 1,00 \\
\hline Incremental Fit Index (IFI) & 0,98 & 0,99 & 1,00 \\
\hline Relative Fit Index (RFI) & 0,93 & 0,91 & 0,99 \\
\hline
\end{tabular}


Table 2: Confirmatory factor analysis fit indices obtained for the refined GENOS EI measurement models

\begin{tabular}{|c|c|c|c|c|c|c|c|}
\hline INDICES & ESA & $\mathbf{E E}$ & EAO & ER & ESM & EMO & ESC \\
\hline \multicolumn{8}{|c|}{ ABSOLUTE FIT MEASURES } \\
\hline$\chi^{2} / \mathrm{df}$ & 1,505 & 1,431 & 1,514 & 0,574 & 1,529 & 1,494 & 3,665 \\
\hline Root Mean Square Error of Approx. (RMSEA) & 0,071 & 0,064 & 0,057 & 0,0 & 0,073 & 0,051 & 0,11 \\
\hline P-Value for Test of Close Fit (RMSEA < 0.05) & 0,11 & 0,17 & 0,34 & 0,89 & 0,088 & 0,44 & 0,093 \\
\hline Root Mean Square Residual (RMR) & 0,048 & 0,053 & 0,034 & 0,018 & 0,049 & 0,037 & 0,053 \\
\hline Standardised RMR & 0,058 & 0,053 & 0,046 & 0,023 & 0,058 & 0,048 & 0,042 \\
\hline Goodness of Fit Index (GFI) & 0,96 & 0,95 & 0,97 & 0,99 & 0,95 & 0,95 & 0,98 \\
\hline \multicolumn{8}{|c|}{ INCREMENTAL FIT MEASURES } \\
\hline Normed Fit Index (NFI) & 0,90 & 0,93 & 0,95 & 0,99 & 0,91 & 0,95 & 0,97 \\
\hline Non-Normed Fit Index (NNFI) & 0,95 & 0,97 & 0,99 & 1,02 & 0,96 & 0,97 & 0,93 \\
\hline Adjusted Goodness of Fit (AGFI) & 0,92 & 0,92 & 0,97 & 0,98 & 0,92 & 0,92 & 0,88 \\
\hline Comparative Fit Index (CFI) & 0,96 & 0,98 & 0,99 & 1,00 & 0,97 & 0,98 & 0,98 \\
\hline Incremental Fit Index (IFI) & 0,97 & 0,98 & 0,99 & 1,01 & 0,97 & 0,98 & 0,98 \\
\hline Relative Fit Index (RFI) & 0,86 & 0,91 & 0,92 & 0,97 & 0,88 & 0,94 & 0,90 \\
\hline
\end{tabular}

\section{Goodness-of-fit: Perceptual depth}

The goodness-of-fit statistics for Perceptual Depth are tabulated in Table 3. Examination of the reported indices indicates that satisfactory fit was achieved between the model and the data.

\section{Measurement models: Factor loadings}

Table 4 presents a summary of the factor loadings obtained for each of the refined measurement models. In all cases, the completely standardised factor loading for each item comprising the measurement model exceeded the $>0.30$ level. This means that all items appear to significantly reflect the dimension they were designed to represent.

\section{Item analysis}

The reliability analysis was done after the refined sub-scale structures had been identified (via CFA and EFA procedures). Each of the scales was viewed as acceptable ( $\alpha$ $>0 ., 0)$ (Malhotra, 2004) (see Table 4).

\section{Goodness-of-fit indices for the structural model}

After interpreting all the fit indices, the conclusion was reached that the structural model fitted the data well. A summary of the most important fit indices is presented in Table 5.

To ensure that a thorough assessment of the structural model was done, it was deemed necessary to investigate the standardised residuals and modification indices. However, there seemed to be no clear suggestion for model modification. Examination of the stem-and-leaf plot indicated that the medium residual is 0.00 . The modest number of extreme residuals corroborated the earlier conclusion that the model fits the data reasonably well.

\section{The relationships between the latent variables}

So far, it has been concluded that the structural model adequately fits the data, as judged by the overall goodnessof-fit measures. However, further assessment of the structural model is necessitated by the need to determine whether the theoretical relationships specified at the conceptualisation stage are indeed supported by the data.

\section{The relationship between negative perceptual depth and perceptual breadth}

A positive relationship was found between negative perceptual depth and perceptual breadth (see Table 6). This subsequently led to the rejection of the null hypothesis $\left(\mathrm{H}_{03}\right.$ : $\left.\gamma_{12}=0\right)$.

In this study, perceptual breadth was defined as the scope of one's perceptions of diversity. An individual's perception of diversity is said to be differentiated when it comprises both positive and negative perceptions of diversity. However, instantaneous evaluations of others is said to largely contribute to the negative impressions and attributes one ascribes to the diversity of others. Human (1996b: 58) believes that, "if an individual is aware of his/her initial biases and preferences, thinking over one's initial judgments adds information and may overrule the unconscious thought". Failure to think further about initial judgments has the power to greatly influence the course of social interaction and the level at which an individual can integrate and understand that people differ in terms of a number of dimensions. 
Table 3 : Confirmatory factor analysis fit indices obtained for perceptual depth (positive and negative)

\begin{tabular}{|c|c|}
\hline INDICES & $\begin{array}{c}\text { Perceptual Depth } \\
\text { (POS and NEG) }\end{array}$ \\
\hline \multicolumn{2}{|c|}{ ABSOLUTE FIT MEASURES } \\
\hline$\chi^{2} / \mathrm{df}$ & 1,83 \\
\hline Root Mean Square Error of Approx. (RMSEA) & 0,059 \\
\hline P-Value for Test of Close Fit (RMSEA < 0.05$)$ & 0,24 \\
\hline Root Mean Square Residual (RMR) & 0,088 \\
\hline Standardised RMR & 0,088 \\
\hline Goodness of Fit Index (GFI) & 0,99 \\
\hline \multicolumn{2}{|c|}{ INCREMENTAL FIT MEASURES } \\
\hline Normed Fit Index (NFI) & 0,98 \\
\hline Non-Normed Fit Index (NNFI) & 0,99 \\
\hline Adjusted Goodness of Fit (AGFI) & 0,99 \\
\hline Comparative Fit Index (CFI) & 0,99 \\
\hline Incremental Fit Index (IFI) & 0,99 \\
\hline Relative Fit Index (RFI) & 0,97 \\
\hline
\end{tabular}

Table 4: Refined measurement scales: factor loadings and reliability

\begin{tabular}{|c|c|c|c|}
\hline SCALE & $\begin{array}{l}\text { NO OF } \\
\text { ITEMS }\end{array}$ & $\begin{array}{c}\text { FACTOR } \\
\text { LOADINGS }\end{array}$ & $\alpha$ \\
\hline \multicolumn{4}{|c|}{ CULTURAL DIVERSITY BELIEF SCALE } \\
\hline Competitive Advantage (CA) & 4 &, $43-, 68$ & ,61 \\
\hline Valuing Individual Differences (VID) & 8 & ,44-,71 & ,76 \\
\hline Tolerance towards Affirmative Action (AA) & 4 &, $48-, 76$ & 70 \\
\hline Total CDBS & 16 & - &, 81 \\
\hline \multicolumn{4}{|c|}{ GENOS EMOTIONAL INTELLIGENCE INVENTORY } \\
\hline Emotional Self Awareness (ESA) & 8 & ,35-,68 & ,66 \\
\hline Emotional Expression (EE) & 9 &, $31-, 61$ & ,73 \\
\hline Emotional Awareness of Others (EAO) & 7 &, $36-, 56$ & 68 \\
\hline Emotional Reasoning (ER) & 5 &, $51-, 59$ & ,68 \\
\hline Emotional Self Management (ESM) & 8 &, $34-, 67$ & ,68 \\
\hline Emotional Management of Others (EMO) & 8 &, $39-, 62$ &, 77 \\
\hline Emotional Self Control (ESC) & 4 &, $45-, 74$ &, 71 \\
\hline Total Genos EI & 49 & - & 82 \\
\hline \multicolumn{4}{|c|}{ REACTION-TO-DIVERSITY-INVENTORY } \\
\hline Positive Perceptual Depth & 5 &, $82-, 89$ & ,92 \\
\hline Negative Perceptual Depth & 5 &, $65-, 95$ & ,91 \\
\hline Perceptual Breadth & 2 & - &, 61 \\
\hline
\end{tabular}

\section{The relationship between emotional intelligence and perceptual breadth}

No significant relationship was found between emotional intelligence and perceptual breadth. Consequently, the null hypothesis was not rejected $\left(\mathrm{H}_{05}: \gamma_{11}=0\right.$ ) (see Table 6$)$. The question invariably arises as to the extent to which this result is due to the inability to successfully operationalise the latent variable of perceptual breadth. However, it is possible that an individual with a high level of EI is not necessarily able to perceive a variety of negative and positive characteristics of diverse others.

Choosing to engage in positive interactions with diverse individuals, coupled with personal knowledge of appropriate emotional management and control, opens new possibilities for the establishment of perceptual breadth by allowing for the creation of perceptions that embrace both positive and negative elements of diversity (Gignac, 2008; Hostager \& De Meuse, 2008). Through direct experiences with diverse individuals, one can thus realise that an orientation towards a more objective view of diversity can enhance one's wellbeing and interpersonal experiences.

\section{The Relationship between Valuing Individual Differences and Perceptual Breadth}

The SEM path was found to be insignificant and the null hypothesis could thus not be rejected $\left(\mathrm{H}_{04}: \beta_{12}=0\right)$ (see Table 7).

A possible explanation for this result is that simply valuing individual differences might not necessarily imply that one has a greater range of diversity perceptions. In fact, the possibility exists that one may choose to only see the positive aspects of diversity, which, in essence, is not optimal, as it becomes very difficult in a social situation to extract the best qualities of each diverse individual. The failure to have an awareness of both positive and negative diversity perspectives prevents building an alliance with others on the basis of similarities, while at the same time being able to accept and value others for being different 
from oneself (Miville et al., 1999). Valuing individual differences therefore does not automatically imply that one has a realistic appreciation of others.

\section{The relationship between emotional intelligence and positive perceptual depth}

A positive relationship was found between emotional intelligence and positive perceptual depth (see Table 6). This subsequently led to the rejection of the null hypothesis $\left(\mathrm{H}_{06}: \gamma_{31}=0\right)$.

It seems that the emotional intelligence of workers may be important in increasing the tendency to view diversity, and experiences arising from diversity, in a more positive light. According to Hostager and De Meuse (2002), greater depth of focus in a positive light indicates greater perceptual complexity in the form of a more positively differentiated view of workplace diversity. Therefore it is argued that individuals with high EI are more inclined to see the diversity of others in a more positive manner, in that they are more accepting of and find value in the differences observed in others.

\section{The relationship between positive perceptual depth and perceptual breadth}

It is evident from the results that this path was found to be significant in the structural model and the null hypothesis could thus be rejected $\left(\mathrm{H}_{02}: \beta_{13}=0\right)$ (see Table 7).

This study confirms the notion that the more one perceives some of the positive attributes of diverse others the more one is inclined to also become aware of other positive characteristics of members of the out-group, as well as to develop a higher level of understanding, acceptance and tolerance of their negative attributes. This involves an active process of controlling how one thinks about others (Human, 2005). By seeing diverse individuals in a more positive light, one becomes able to have a greater range of diversity perceptions. Thus, the more one views the diversity of others in a more positive manner, the more one is able to develop a more objective view of diversity by focusing on both positive and negative perceptions of diversity (Miville et al., 1999).

Supporting of Hypotheses 2 and 6 led to the conclusion that Hypothesis 13 was also confirmed. Thus, the relationship between emotional intelligence and perceptual breadth is seen as mediated by positive perceptual depth.

\section{The relationship between valuing individual differences and positive perceptual depth}

The SEM results confirmed that a significant path existed between valuing individual differences and positive perceptual depth. Thus the null hypothesis could be rejected $\left(\mathrm{H}_{08}: \beta_{32}=0\right)$ (see Table 7).

This implies that the ability to understand and find value in the individual differences of people directly increases the degree to which diversity, in itself, is viewed in a positive light. This is extremely important within the organisational environment, as a congruent understanding of other's views should enable one to more accurately infer others' intentions and meanings, facilitating fluent, efficient interaction and helping others to utilise their diverse abilities to accomplish their collective goals (Human, 1996b).

Similarly, the present study confirmed Hunsberger, Lea, Pancer, Pratt and McKenzie's (1992) assertion that understanding, accepting and appreciating the diversity of others may reflect the cognitive capacity to think of others in a more multidimensional and positive manner.

Developing a more complex perception of diversity in a positive manner and, hence, a more positive attitude towards diversity, involves the need to become more socially familiar with diverse individuals (Crush, 2008). The more socially familiar one becomes with diverse members of the organisation, the more likely it is that one's attitude towards such individuals will begin to change positively through beginning to take note of shared similarities and coming to understand and appreciate existing differences.

Table 5: Goodness-of-fit indices for structural model

\begin{tabular}{l|c}
\hline \multicolumn{1}{c}{ INDICES } & Structural Model \\
\hline \multicolumn{1}{c}{ ABSOLUTE FIT MEASURES } & 2,32 \\
\hline$\chi^{2} / \mathrm{df}$ & 0,075 \\
\hline Root Mean Square Error of Approx. (RMSEA) & 0,12 \\
\hline P-Value for Test of Close Fit (RMSEA < 0.05) & 0,056 \\
\hline Root Mean Square Residual (RMR) & 0,056 \\
\hline Standardised RMR & 0,97 \\
\hline Goodness of Fit Index (GFI) & \\
\hline \multicolumn{1}{c}{ INCREMENTAL FIT MEASURES } \\
\hline Normed Fit Index (NFI) & 0,92 \\
\hline Non-Normed Fit Index (NNFI) & 0,91 \\
\hline Comparative Fit Index (CFI) & 0,95 \\
\hline Incremental Fit Index (IFI) & 0,96 \\
\hline
\end{tabular}


Table 6: Unstandardized gamma $(\Gamma)$ matrix

\begin{tabular}{c|c|c}
\hline & Negative Perceptual Depth & Emotional Intelligence \\
\hline Valuing Individual Differences & - & $\mathbf{0 , 1 7}$ \\
& & $(0,06)$ \\
& & $2,64^{*}$ \\
\hline Perceptual Breadth & $\mathbf{0 , 5 3}$ & $\mathbf{0 , 0 2}$ \\
& $(0,06)$ & $0,05)$ \\
\hline Positive Perceptual Depth & $9,61^{*}$ & $\mathbf{0 , 1 4}$ \\
& - & $(0,07)$ \\
\hline
\end{tabular}

Note: Completely standardized path coefficients in bold type; standard error estimates in brackets; t-values $\geq|1,96|$ indicate significant parameter estimates $(\mathrm{p}<0,05) *$

The results make it clear that the relationship between valuing individual differences and perceptual breadth is mediated by positive perceptual depth. Consequently, Hypothesis 14 is confirmed.

\section{The relationship between emotional intelligence and valuing individual differences}

Support was found for the postulated positive relationship between emotional intelligence and valuing individual differences. The null hypothesis $\left(\mathrm{H}_{07}: \gamma_{21}=0\right)$ could thus be rejected (see Table 6).

This is an important contribution, as the results clearly support the notion that emotional intelligence can enhance the value found within the individuality of others. A possible reason for this conclusion is that emotions are believed to organise and coordinate ongoing psychological action (i.e. attention, motivation) so that individuals are able to respond more effectively to the complexities characterising social life and behaviours at work (Cottrell \& Neuberg, 2005). The study confirms Carmeli's (2003) statement that EI is a major contributing factor towards the development and maintenance of positive attitudes. The results demonstrate that EI is a key ingredient in the process of developing and maintaining social relationships in work groups (Antonakis et al., 2009). It seems that emotionally intelligent individuals find greater value in individual differences and, as a result, are better able to master their interactions with diverse others in a more constructive manner (Elfenbein \& Ambady, 2002; Murphy \& Janeke, 2009; Suliman \& Al-Shaikh, 2007).

\section{The relationship between valuing individual differences and tolerance of affirmative action}

A positive relationship was found between valuing individual differences and tolerance of affirmative action. Thus the null hypothesis was rejected $\left(\mathrm{H}_{09}: \beta_{42}=0\right.$ ) (see Table 7).

According to Montei et al. (1996), the value one ascribes to individual differences, and invariably one's attitude towards diversity, refers to the degree to which one is able to accept minorities, primarily women and the disabled, as well as the various racial groups in the workplace. This includes acceptance of such individuals as co-workers, supervisors and those in any other work-related roles. Moreover, valuing individual differences includes the degree to which one accepts the increased hiring of minorities. The present study has good reason to support the above statement by Montei, Adams and Eggers (1996) and is particularly relevant as it implies that the more one is able to value another's individuality, the more likely it is that one will be able to understand and accept affirmative action in the workplace.

The results indicate that the relationship between emotional intelligence and tolerance towards affirmative action is mediated by valuing individual differences. Hypothesis 11 is therefore corroborated.

\section{The relationship between valuing individual differences and diversity as a competitive advantage}

The results revealed that the path coefficients between valuing individual differences and diversity as a competitive advantage were significant. Thus, the null hypothesis was rejected $\left(\mathrm{H}_{010}: \beta_{52}=0\right)$ (see Table 7).

When managed properly, a diverse workforce that has the ability to find value in the individuality of others results in a competitive advantage for the organisation (Montei et al., 1996). This study has clearly confirmed this statement and further supports the viewpoint held by Cox and Blake (as cited by Rentsch et al., 1995: 3), who suggest that valuing diversity in organisations involves all cultural groups respecting, valuing and learning from one another; all organisational members identifying with organisational goals; and eliminating prejudice and discrimination. This, in turn, implies that one will be able to comprehend the added value that diverse perspectives, skills, abilities, and even personalities, could bring to the organisation and encourage proactive behaviour in terms of capitalising on individual differences. The utilisation of diversity is likely to be followed by a heightened sense of unity, respect and understanding and enhanced organisational performance (Johnson \& Johnson, 2006; Yukl, 2010).

The results have shown that the relationship between emotional intelligence and diversity as a competitive advantage is mediated by valuing individual differences. Thus, Hypothesis 12 is supported. 


\section{Suggestions for future research}

The results of the study provided valuable insight into the relationships between attitude towards diversity, emotional intelligence and diversity complexity cognition. There, however, are several recommendations for future studies. A longitudinal study of the proposed conceptual model should be undertaken in order to make more convincing causal inferences.
In addition, future studies should use a sample that is more representative of specific industrial sectors in the South African economy. Further psychometric refining of the measuring instruments used in this study is also required.

Future research should also consider the possibility of expanding the theoretical model by incorporating additional latent variables like social identity complexity, cultural experiences, values and history of conflict, to explain additional variance in the attitude towards diversity.

Table 7: Unstandardized beta (B) matrix

\begin{tabular}{c|c|c}
\hline & Valuing Individual Differences & Positive Perceptual Depth \\
\hline Affirmative Action & $\mathbf{0 , 3 0}$ & - \\
& $(0,06)$ & - \\
\hline Competitive Advantage & $4,84^{*}$ & $\mathbf{0 , 6 7}$ \\
& $(0,06)$ & $\mathbf{0 , 4 2}$ \\
\hline Perceptual Breadth & $11,73^{*}$ & $(0,05)$ \\
& $\mathbf{0 , 0 2}$ & $7,67^{*}$ \\
\hline Positive Perceptual Depth & $(0,05)$ & - \\
& 0,33 & $\mathbf{0 , 1 6}$ \\
\hline
\end{tabular}

Note: Completely standardized path coefficients in bold type; standard error estimates in brackets; t-values $\geq 1,96 \mid$ indicates significant parameter estimates $(\mathrm{p}<0,05)^{*}$

\section{Managerial implications and conclusion}

Managers play an essential role in providing equal opportunity and elimination of unfair discrimination in selection and promotion decisions. Management should develop an organisational culture in which cultural awareness, sensitivity and fairness can prosper, which, in turn, would enable all diverse groups to respect, value and learn from one another.

Organisations should provide employees with adequate training in emotional intelligence to enhance members' understanding, appreciation and acceptance of the individuality of others. The development of employees' emotional intelligence and their valuing of workplace diversity would lead to a more positively differentiated view of diversity, and, in turn, to a better understanding of a larger reach of diversity dimensions (i.e. values, beliefs, traditions). Diversity training programmes should create a higher level of self-awareness about stereotyping and intolerance, as well as a better understanding and appreciation of cultural differences and how to respond to them in the workplace.

To increase their employees' perception of diversity as a competitive advantage, as well as elevate their tolerance of affirmative action, organisations should, firstly, train their employees in valuing diversity. Managers should perceive diversity as a competitive advantage since it offers important insights into problems and challenges because it counteracts groupthink, thereby enhancing organisational creativity and decision making. Affirmative action programmes are likely to be more successful if the need for them is clearly understood by employees, and ways are found to encourage affirmative action without imposing reverse discrimination (Yukl, 2010).

Managers who understand and can diagnose their employees' attitudes towards diversity may be able to predict the level of success of their diversity interventions and may be better equipped to link diversity initiatives to other aspects of organisational development, which could eventually lead to a healthier work environment.

\section{References}

Antonakis, J., Ashkanasy, N.M. \& Dasborough, M.T. 2009. 'Does leadership need emotional intelligence?', Leadership Quarterly, 20: 247-261.

Boon, M. 2007. The African way: The power of interactive leadership. Cape Town: Zebra Press

Brewer, M.B. \& Pierce, K.P. 2005. 'Social identity complexity and outgroup tolerance', Social Psychology Bulletin, 31(3): 1-10.

Carmeli, A. 2003. 'The relationship between emotional intelligence, work attitudes, behavior and outcomes: An examination among senior managers', Journal of Managerial Psychology, 18(8): 788-813.

Cottrell, C.A., \& Neuberg, S.L. 2005. 'Different emotional reactions to different groups: A sociofunctional threat-based approach to "prejudice",'Journal of Personality and Social Psychology, 88(5): 770-789. 
Crush, J. 2008. 'Immigration, xenophobia and human rights in South Africa' Southern African migration Project: Migration Policy Series No. 22. [online] URL:http://www.queensu.ca/policyseriess.

DeGuara, D. \& Stough, C. 2002. Examining the relationship between emotional intelligence and workplace performance. Swinburne: Organisational Psychology Research Unit, Swinburne University, Australia.

De Meuse, K.P. \& Hostager, T.J. 2001. 'Developing an instrument for measuring attitudes toward and perceptions of workplace diversity: An initial report', Human Resource Development Quarterly, 12(1): 33-52.

Elfenbein, H.A. \& Ambady, N. 2002. 'Predicting workplace outcomes from the ability to eavesdrop on feelings', Journal of Applied Psychology, 87(5): 963-971.

Fiske, S.T. \& Lee, T.L. 2008. 'Stereotypes and prejudice create workplace discrimination'. In Brief, A.P. (Ed.). Diversity at work. Cambridge: Cambridge University Press.

Gignac, G.E. 2008. 'Genos emotional intelligence inventory: Technical manual'. Unpublished manuscript, Genos Head Office, Sydney, Australia.

Goleman, D., Boyatzis, R. \& McKee, A. 2002. The new leaders: Transforming the art of leadership into the science of results. London: Little Brown.

Hair, J.F., Black, W.C., Babin, B.J., Anderson, R.E. \& Tatham, R.L. 2006. Multivariate data analysis. $6^{\text {th }}$ Edition. Upper Saddle River, New Jersey: Prentice Hall.

Harvey, C.P. \& Allard, M.J. 2005. Understanding and managing diversity: Readings, cases and exercises. New Jersey: Pearson Prentice Hall.

Heine, S.J., Proulx, T. \& Vohs, K.D. 2006. 'The meaning maintenance model: On the coherence of social motivations', Personality and Social Psychology Review, 10(2): 88-110.

Homan, A.C., Van Knippenberg, D., Van Kleef, G.A. \& De Dreu, C.K.W. 2007. 'Bridging faultlines by valuing diversity: Diversity beliefs, information elaboration, and performance in diverse work groups', Journal of Applied Psychology, 92(5): 1189-1199.

Hostager, T.J. \& De Meuse, K.P. 2002. 'Assessing the complexity of diversity perceptions: Breadth, depth and balance', Journal of Business and Psychology, 17(2): 189206.

Hostager, T.J. \& De Meuse, K.P. 2008. 'The effects of a diversity learning experience on positive and negative diversity perceptions', Journal of Business and Psychology, 23(2): 127-139.

Human, L. 1996a. 'Managing workforce diversity: a critique and example from South Africa', International Journal of Manpower, 17(4/5): 46-64.
Human, L. 1996b. Contemporary conversations: Understanding and managing diversity in the modern world. Senegal: Gorée Institute.

Human, L. 2005. 'Current issues and practices for global diversity'. Paper presented at the American Society for Training and Development's global conference and exhibition. Cape Town, February 2-4.

Hunsberger, B., Lea, J., Pancer, S.M., Pratt, M. \& McKenzie, B. 1992. 'Making life complicated: Prompting the use of integratively complex thinking', Journal of Personality, 60(1): 95-114.

Johnson, D.W. \& Johnson, F.P 2006. Joining together: group theory and group skills, $\left(9^{\text {th }}\right.$ Edition). Boston: Pearson International Edition.

Jöreskog, K.G. \& Sörbom, D. 1996. LISREL 8: User's reference guide. Chicago: Scientific Software International.

Kelloway, E.K. 1998. Using LISREL for structural equation modeling: A researcher's guide. United States of America: SAGE.

Malhorta, N.K. 2004. Marketing research: An applied orientation (4 ${ }^{\text {th }}$ Edition). Upper Saddle River, NJ: Pearson Education Inc.

Miville, M.L., Gelso, C.J., Pannu, R., Liu, W., Touradji, P., Holloway, P. \& Fuertes, J.N. 1999. 'Appreciating similarities and valuing differences: The Miville-Guzman Universality Diversity Scale', Journal of Counseling Psychology, 46(3): 291-307.

Montei, M.S., Adams, G.A. \& Eggers, L.M. 1996. 'Validity of scores on the Attitudes Towards Diversity Scale (ATDS),' Educational and Psychological Measurement, 56(2): 293-302.

Murphy, A. \& Janeke, H.C. 2009. 'The relationship between thinking styles and emotional intelligence: An exploratory study', South African Journal of Psychology, 39(3): 357375 .

Nunnaly, J.C. 1978. Psychometric theory ( $2^{\text {nd }}$ Edition). New York: McGraw-Hill.

Plaut, V.C. 2002. 'Cultural models of diversity in America: The psychology of difference and inclusion'. In Shweder, R.A., Minow, M. and Markus, H.R. (Eds.). Engaging cultural differences: The multicultural challenge in liberal democracies. New York: Russel Sage Foundation, pp. 365395.

Polzer, J.T. \& Caruso, H.M. 2008. 'Identity negotiation processes amidst diversity'. In Brief, A.P. (Ed.). Diversity at work. Cape Town: Cambridge University Press, pp. 89-126.

Rentsch, J.R., Turban, D.B., Hissong, A.A., Jenkins, N.M. \& Marrs, M.B. 1995. 'Development of the Cultural Diversity Beliefs Scale'. Paper presented at the Tenth 
Annual Conference of the Society for Industrial and Organizational Psychology, Orlando, Florida.

Robertson, Q.M. \& Stevens, C.K. 2006. 'Making sense of diversity in the workplace: Organizational justice and language abstraction in employees' accounts of diversityrelated incidents', Journal of Applied Psychology, 91(2): 379-391.

Salovey, P. \& Mayer, J.D. 1990. 'Emotional intelligence', Imagination, Cognition and Personality, 9(3): 185-211.

Sanchez-Burks, J., Blount, S. \& Bartel, C.A. 2009. 'Performance in intercultural interactions at work: Crosscultural differences in response to behavioral mirroring', Journal of Applied Psychology, 94(1): 216-223.

Sawyerr, O.O., Strauss, J. \& Yan, J. 2005. 'Individual value structures and diversity attitudes: The moderating effects of age, gender, race, religiosity', Journal of Managerial Psychology, 20(6): 498-521.

Seyman, O.A. 2006. 'The cultural diversity phenomenon in organisations and different approaches for effective cultural diversity management: A literary review', Cross Cultural Management: An International Journal, 13(4): 296-315.

Strauss, J.P., Connerley, M.L. \& Ammermann, P.A. 2003. "The "threat hypothesis," personality, and attitudes toward diversity', Journal of Applied Behavioral Science, 39(1): 3252.

Suliman, A.M. \& Al-Shaikh, F.N. 2007. 'Emotional intelligence at work: Links to conflict and innovation,' Employee Relations, 29(2): 208-220.

Yukl, G. 2010. Leadership in organizations. Upper Saddle River, NJ: Pearson. 